\title{
Crystalline Lens Vitamin C Levels in Cataract Surgical Patients
}

\section{Beatrice Oluyomi Emma-Okon ${ }^{1 *}$, Oluwatoyin Helen Onakpoya ${ }^{2}$, Babatope Ayodeji Kolawole ${ }^{3}$, Mobolade Olasunkanmi Akinde², Oluwadare Joel Agunbiade1, Funmilayo Abidemi Owolabi ${ }^{3}$}

\author{
${ }^{1}$ Department of Medical Biochemistry, Obafemi Awolowo University, Ile-Ife, Nigeria \\ ${ }^{2}$ Department of Ophthalmology, Obafemi Awolowo University, Ile-Ife, Nigeria \\ ${ }^{3}$ Department of Medicine, Obafemi Awolowo University, Ile-Ife, Nigeria \\ Email: ^oemmaokon@gmail.com, *uvtoyin2@yahoo.co.uk
}

How to cite this paper: Emma-Okon, B.O., Onakpoya, O.H., Kolawole, B.A., Akinde, M.O., Agunbiade, O.J. and Owolabi, F.A. (2021) Crystalline Lens Vitamin C Levels in Cataract Surgical Patients. Open Journal of Ophthalmology, 11, 134-142. https://doi.org/10.4236/ojoph.2021.112010

Received: April 2, 2021

Accepted: May 15, 2021

Published: May 18, 2021

Copyright $\odot 2021$ by author(s) and Scientific Research Publishing Inc. This work is licensed under the Creative Commons Attribution International License (CC BY 4.0).

http://creativecommons.org/licenses/by/4.0/

\begin{abstract}
To determine the amount of Vitamin C in the lenses of Diabetic and NonDiabetic Patients with Operable Cataract and ascertain association between Vitamin C levels and Blood Glucose, Glycated Haemoglobin and Intraocular pressure. Thirty Diabetic and Thirty Non-Diabetic Patients cataract surgical patients were matched for age and sex and selected for the study. Plasma fasting blood glucose and whole blood glycated Haemoglobin levels were determined by glucose oxidase enzymatic assay and immunodetection methods respectively. Cataractous lens samples obtained during surgery were weighed and homogenized in 10 volumes of phosphate buffer $\mathrm{pH} 7$ and the resulting homogenate centrifuged at $18,000 \mathrm{~g}$ for 5 minutes at $4^{\circ} \mathrm{C}$, separated and supernatant stored at $-80^{\circ} \mathrm{C}$. Vitamin $\mathrm{C}$ assay was carried out using commercial assay kits. Data was analyzed using SPSS version 23. Age range of participants was 55 - 83 years, with a mean of $66.7 \pm 1.8$ years. Mean Vitamin C levels in the Diabetic and Non-Diabetic groups were $49.5 \mu \mathrm{g} / \mathrm{g} \pm 6.47$ and $57.02 \mu \mathrm{g} / \mathrm{g} \pm$ 8.0 respectively. Although the Non-diabetic group had higher levels of Vitamin $C$, the difference was not significant. Levels of Vitamin $C$ found in both groups are much lower than what has previously been reported in Literature for clear lenses. There was negative association between Vitamin C and Glucose, Glycated Haemoglobin and Intraocular Pressure. Vitamin C supplementation may be useful in prolonging incidence of cataract in both aging and diabetic Nigerian populations. Larger study involving estimation of Vitamin C in both lens and Plasma samples is desirable.
\end{abstract}

\section{Keywords}

Cataract, Diabetes, Antioxidants, Vitamin C 


\section{Introduction}

Cataract, the clouding or opacity of the crystalline lens is the leading cause of blindness globally with attendant profound social and economic burden. It has been estimated that cataract accounted for $47.8 \%$ of the 37 million people who were blind worldwide in 2002 [1]. By 2010, studies indicated that 10.8 million people were blind and 35.1 million visually impaired as a result of cataract [2] [3]. This number is expected to increase to 40 million in 2025 as the population grows and ages with greater life expectancies [4]. In many countries, cataract surgery is one of the most commonly performed procedures, with about 8 million cataract operations performed annually worldwide and an additional 10 million people added to a backlogged system due to lack of sufficient and appropriate facilities [5]. In Nigeria, the most recent survey revealed that $1.8 \%$ of adult Nigerians aged 40 and above had cataract-related blindness [5] while other regional survey reports gave values ranging between $2.1 \%$ and $4.1 \%$ [6] [7] [8]. The major predisposing factors for cataract are age and diabetes mellitus. While the majority of cataracts are due to the aging process, it is reported that cataract occurs at an earlier age and 2 - 5 times more frequently in people with DM than their nondiabetic counterparts [9]. It has been estimated that delaying the onset of cataract by 10 years would halve its incidence and therefore reduce the need for, and cost associated with cataract surgery [10].

Oxidative stress is an active player in both age-related and diabetic cataracts. This results when cellular antioxidant defense mechanisms are unable to keep pace with the detoxification of reactive oxygen intermediates produced, causing extensive damage to proteins and leading to irreversible deleterious effects. The pathogenesis of diabetic cataract is attributed to the accumulation of sorbitol, produced from excess glucose by the enzyme aldose reductase, initiating osmotic stress and resulting in fluid accumulation, lens fibre cell swelling and tissue liquefaction [11] [12]. Reports also suggest that hyperglycemia results in increased polyol pathway activity which generates both osmotic and oxidative stress in the diabetic lens. Due to the proven association between lens cataract and oxidative damage, antioxidant supplementation has been promoted as a treatment strategy to delay the onset of cataract [13] [14] [15].

The presence of antioxidant micronutrients in the lens is well reported. Animal experiments have identified the protective effects of vitamin $C$, which is considered the most prominent water-soluble molecule with antioxidant properties against cataract [16] [17]. The high concentrations of ascorbate present in normal lenses, cornea, and aqueous humor (50-fold higher than what obtains in human plasma, [18] [19] suggests that ascorbic acid is of relevant importance to the well-being of the eye. Vitamin $C$ is said to account for $75 \%$ of the antioxidant potential in the aqueous humor and to be one of the agents that protect the lens and trabecular meshwork from reactive oxygen species (ROS) [20] [21]. It has been suggested that Vitamin $C$ acts as a physiological sunscreen to protect the eye from UV induced oxidative damage and to generate Vitamin E and gluta- 
thione to further increase antioxidant capacity. Some studies have indicated that vitamin $C$ levels in the lens decrease with advancing age and that this decrease is associated with increase in cataract severity [22]. Since the concentration of vitamin $\mathrm{C}$ in the lens has been found to be related to vitamin $\mathrm{C}$ supplementation [23], vitamin C supplementation may help replenish and restore vitamin C levels in lenses of the elderly and diabetic populations and hence delay the onset of cataract. A recent study also found that dietary vitamin $\mathrm{C}$ has a protective effect against nuclear lens opacity and delayed its progression [24]. The Blue Mountains Eye Study found that vitamin $\mathrm{C}$ intake, through both diet and supplements together, resulted in a lower nuclear cataract incidence over 10 years [25]. Presently, documentation of baseline Vitamin C levels in cataractous lenses of Nigerian patients is not available. The peculiarities of specific genetic make-up as well as nutritional lifestyle of Nigerians makes it necessary to provide this data. This study therefore seeks to measure levels of vitamin $\mathrm{C}$ in lenses of diabetic and non-diabetic elderly cataract patients and compare with levels previously established for people with clear lenses. Levels of vitamin $\mathrm{C}$ in the two groups will also be compared and associations between vitamin $C$ levels and various ocular parameters ascertained. This is expected to provide evidence based treatment practice.

\section{Methods}

This study was conducted at the Ophthalmology unit of the Obafemi Awolowo University Teaching Hospital and the Department of Medical Biochemistry, Obafemi Awolowo University, Ile-Ife, Nigeria. Ethical approval was obtained from the Ethics Committee of OUATHC. Subjects included consenting cataract surgical patients in the Department of ophthalmology who met the inclusion criteria (Operable cataract, not on antioxidant supplementation, not less than 50 years old) for the study. Thirty Type 2 diabetic patients (group A) and 30 non-diabetic patients (group B) who were matched for age and sex made up the study sample. Consecutive cataract surgical patients making the inclusion criteria were recruited into the study until the sample size was attained. Persons with post uveitic cataract, posttraumatic cataract and those who had been on vitamin $\mathrm{C}$ supplement within the past three months were excluded from the study.

Demographic information and medical history of all participants were recorded in a predesigned proforma. All patients had lens examination and grading carried out following dilatation of the pupil using slit lamp bio-microscope (Carl zeis). Blood samples were obtained in the morning of the surgery for assessment of fasting blood sugar and glycated hemoglobin. The patients subsequently had routine small incision cataract surgery and nucleus delivery was achieved following can opener capsulotomy by gentle depression of nucleus to tilt into the anterior chamber with the aid of an irrigating Vectis. Cataractous lens samples including the nucleus, cortex and remnant of anterior capsule were transported to the laboratory in an ice bucket. The lens samples were weighed and homoge- 
nized in 10 volumes of phosphate buffer $\mathrm{pH} 7.2$ consisting of $10 \mathrm{mM}$ sodium phosphate $1 \mathrm{mM}$ EDTA and $0.2 \mathrm{mM} \mathrm{BHT}$. The resulting homogenate was centrifuged at $18,000 \mathrm{~g}$ for 5 minutes at $4^{\circ} \mathrm{C}$ and the supernatant collected into plain tubes. This was stored at $-80^{\circ} \mathrm{C}$ until time of analysis.

Fasting blood glucose was estimated using the glucose oxidase method while $\mathrm{HbAlc}$ was measured using an affinity assay kit which is based on the specific interaction between glycated Haemoglobin and boronate ion immobilized within an agarose gel. The reaction solution contains agents that lyse erythrocytes and bind Haemoglobin specifically as well as a boronate resin that binds cis-diols of glycated Haemoglobin.

Vitamin C assay was carried out using colorimetric assay kits obtained from Elabscience Biotechnology Inc. Vitamin $\mathrm{C}$ in the lens homogenate converts $\mathrm{Fe}^{2+}$ component of the assay kit to $\mathrm{Fe}^{3+}$ which reacts with phenantroline dye and produces a pink colour whose intensity is proportional to the amount of Vitamin $C$ in the sample.

Data was analysed using SPSS version 23 [26]. Results are presented as mean and standard error of mean. $\mathrm{P}<0.05$ was considered significant.

\section{Results}

A total of 60 patients participated in the study with an age range of 55 - 83 years and a mean age of $66.7 \pm 1.8$ years. In group A (the Diabetic group), the mean age was $66.1 \pm 1.2$ years while that of group B (the Non-Diabetic group) was 67.2 \pm 1.4 years (Table 1 ). There were 16 males and 14 females in the diabetic group while the non-diabetic group had 17 males and 13 females. Most patients in the diabetic group (90\%) were being managed on dietary modification and oral hypoglycemic agents while the remaining $10 \%$ were on insulin therapy in addition to the above. The preoperative visual acuity was in the blindness range for most (96.7\%) of the respondents. Prevalence of hypertension in the diabetic and nondiabetic groups was $64.3 \%$ and $17.4 \%$ respectively.

Table 2 \& Table 3 show the mean fasting blood sugar and HBA1c and Vitamin C levels in the two groups. An average lens sample weighed $0.2 \mathrm{~g}$ and mean protein concentration of diabetic and non-diabetic cataractous lens were $20.27 \pm$ 2.44 and $16.83 \pm \mathrm{mg} / \mathrm{g}$, respectively. Table 4 shows the association between lens

Table 1. Age distribution of participants.

\begin{tabular}{cccc}
\hline Age group & $\begin{array}{c}\text { Diabetic Cataract Group } \\
\mathbf{n}(\%)\end{array}$ & $\begin{array}{c}\text { Non-Diabetic Cataract Group } \\
\mathbf{n}(\%)\end{array}$ & $\begin{array}{c}\text { Total } \\
\mathbf{n}(\%)\end{array}$ \\
\hline Mean \pm SEM & $66.1 \pm 1.2$ & $67.2 \pm 1.4$ & $66.7 \pm 1.8$ \\
$50-59$ & $4(13.3)$ & $6(20.0)$ & $10(16.7)$ \\
$60-69$ & $17(56.7)$ & $14(46.7)$ & $31(51.7)$ \\
$70-79$ & $7(23.3)$ & $7(23.3)$ & $14(23.3)$ \\
$80+$ & $2(6.7)$ & $3(10.0)$ & $5(8.3)$ \\
Total & $30(100.0)$ & $30(100.0)$ & $60(100.0)$ \\
\hline
\end{tabular}


Table 2. Mean glucose and glycated haemoglobin levels in diabetic and non-diabetic operable cataract patients.

\begin{tabular}{cccccccc}
\hline Group & $\mathrm{N}$ & $\begin{array}{c}\text { Mean Glucose Level } \\
(\mathrm{mM} / \mathrm{L}) \pm \mathrm{SEM}\end{array}$ & $\mathrm{t}$ & p-value & $\begin{array}{c}\text { Mean HBA1c } \\
\text { level (\%) } \pm \text { SEM }\end{array}$ & $\mathrm{t}$ & p-value \\
\hline Diabetic & 30 & $6.22 \pm 0.28$ & & & $5.51 \pm 0.27$ & & \\
Non-Diabetic & 30 & $4.67 \pm 0.19$ & 4.640 & $0.001^{*}$ & $4.67 \pm 0.09$ & & $0.005^{*}$ \\
\hline
\end{tabular}

${ }^{\star}$ Significant at $0.05 \%$ confidence interval.

Table 3. Mean vitamin C levels in diabetic and non-diabetic operable cataract patients.

\begin{tabular}{ccccc}
\hline Group & Observations & $\begin{array}{c}\text { Mean Lens Vitamin C } \\
\text { levels }(\mu \mathrm{g} / \mathrm{g}) \pm \text { SEM }\end{array}$ & $\mathrm{T}$ & p-value \\
\hline Diabetic & 30 & $49.50 \pm 6.47$ & 0.731 & 0.468 \\
Non-Diabetic & 30 & $57.02 \pm 8.0$ & &
\end{tabular}

Table 4. Correlation showing association/degree of relationship between vitamin $\mathrm{C}$ and selected parameters.

\begin{tabular}{ccc}
\hline & vitamin C ug/g & p-value \\
\hline Glucose $(\mathrm{mM} / \mathrm{L})$ & -0.0713 & 0.589 \\
HBA1C $(\%)$ & -0.1787 & 0.172 \\
Intra Ocular Pressure $(\mathrm{mmHg})$ & -0.1725 & 0.191 \\
\hline
\end{tabular}

Vitamin C levels, Glucose, Glycated Haemoglobin, Total lens Protein and Intraocular Pressure.

\section{Discussion}

Cataract will remain a serious healthcare and socioeconomic burden, in terms of both healthcare provision and blindness in both advanced and developing countries. Although it is well known that lens contains as much as 50 times the concentration of Vitamin C present in plasma, plasma samples were used in most of the work carried out on estimations of Vitamin C levels in Cataract Patients, making it rather difficult to compare our values with established reference ranges. However, we found an old but very reliable study in which Vitamin C Level in clear lens samples were estimated. This study came up with values between 260 $460 \mu \mathrm{g} / \mathrm{g}$ which is much higher than the values found in this study mean of 47.55 and $58.99 \mu \mathrm{g} / \mathrm{g}$ for diabetic and non-diabetic cataract patients respectively [27]. Other Authors reported that the physiological concentration of Vitamin C in the lens is $1-2 \mathrm{mM}(0.174-0.348 \mathrm{~g})$ [28], The fact that there was no significant difference in the levels of Vitamin $C$ found in the two groups underscores the need for supplementation in both elderly and diabetic Nigerian populations. A study which analysed antioxidant markers such as catalase, $\mathrm{Cu}$ - $\mathrm{Zn}$ superoxide dismutase in these two groups found diabetic patients having significantly lower levels than their non-diabetic counterparts and proposed that elevated glucose levels might be involved in the insufficient production of antioxidant enzymatic activ- 
ity [29]. Canadananovic et al. also reported a decrease in the amount of vitamin $\mathrm{C}$ in aqueous humour with age, and suggests that this decrease could play a role in the susceptibility of the older population to cataract formation [30].

The use of low dose Vitamin C supplements has also been reported to reduce the risk of age-related Cataract in Sweden Males [31].

There was negative association between Vitamin C levels and plasma Glucose and HBA1c levels. This suggests that hyperglycemia depletes vitamin $\mathrm{C}$ levels and is in agreement with previous reports that hyperglycemia impairs the pro-oxidation of antioxidant balance, increasing free radical generation and reducing antioxidant levels [32].

Negative association was also found between Vitamin C levels and intraocular pressure. Oxidative stress has been related to cell death in glaucoma, and although there are differing opinions on the effect of antioxidant therapy in this disease, it is desirable to pursue research in this area in view of rising cases of irreversible blindness occasioned by glaucoma across Africa and the rest of the globe.

This study is the first to provide data on Vitamin C levels in lenses of Nigerian Cataract Patients. We conclude that Vitamin C supplementation may be of help in delaying incidence of cataract and improving quality of life in both aging and diabetic Nigerian populations. This is against the backdrop of the general consensus that a well-balanced diet rich in fruit and vegetables which contain high levels of Vitamin $\mathrm{C}$ may be a more optimal approach towards slowing down the progression of age related cataracts. It is desirable to estimate the levels of Vitamin $\mathrm{C}$ in both lens and Plasma samples using a larger sample size and across various ethnic groups in order to firmly establish a range of this Vitamin among the study groups.

\section{Acknowledgements}

Authors are grateful to the Authorities of Obafemi Awolowo University for providing funds for this Research work through the Tertiary Education Fund (TETFUND), Nigeria (2015-2016 TETFUND Research Projects/IBR Intervention).

\section{Conflicts of Interest}

The authors declare no conflicts of interest regarding the publication of this paper.

\section{References}

[1] Resnikoff, S., Pascolini, D., Etya'ale, D., Kocur, I., Pararajasgaram, R., Pokharel, G.P. and Mariotti, S.P. (2004) Global Data on Visual Impairment in the Year 2002. Bulletin of the World Health Organization, 82, 844-851. https://doi.org/10.1076/opep.11.2.67.28158

[2] Khairallah, M., Kahloun, R., Bourne, R., Limburg, H., Flaxman, S.R., Jonas, J.B., Keeffe, J., Leasher, J., Naidoo, K., Pesudovs, K., Price, H., White, R.A., Wong, T.Y., 
Resnikoff, S. and Taylor H.R. (2015) Number of People Blind or Visually Impaired by Cataract Worldwide and in World Regions, 1990 to 2010. Investigative Ophthalmology \& Visual Science, 56, 6762-6769. https://doi.org/10.1167/iovs.15-17201

[3] Bourne, R.R., Stevens, G.A., White, R.A., Smith, J.L., Flaxman, S.R., Price, H., Jonas, J.B., Keeffe, J., Leasher, J., Naidoo, K., Pesudovs, K., Resnikoff, S. and Taylor, H.R. (2013) Causes of Vision Loss Worldwide, 1990-2010: A Systematic Analysis. The Lancet Global Health, 1, e339-e349. https://doi.org/10.1016/S2214-109X(13)70113-X

[4] Pascolini, D. and Mariotti, S.P. (2012) Global Estimates of Visual Impairment: 2010. British Journal of Ophthalmology, 96, 614-618. https://doi.org/10.1136/bjophthalmol-2011-300539

[5] Taylor, H.R. (2000) Cataract: How Much Surgery Do We Have to Do? British Journal of Ophthalmology, 84, 1-2. https://doi.org/10.1136/bjo.84.1.1

[6] Abdull, M.M., Sivasubramaniam, S.G., Murthy, V.S., Gilbert, C., Abubakar, T., Ezelum, C., Mansur, M. and Rabiu, M.M. (2009) Causes of Blindness and Visual Impairment in Nigeria: The Nigeria National Blindness and Visual Impairment Survey. Investigative Ophthalmology \& Visual Science, 50, 4114-4120. https://doi.org/10.1167/iovs.09-3507

[7] Rabiu, M.M and Muhammed, N. (2008) Rapid Assessment of Cataract Surgical Services in Birnin-Kebbi Local Government Area of Kebbi State, Nigeria. Ophthalmic Epidemiology, 15, 359-365. https://doi.org/10.1080/09286580802399078

[8] Rabiu, M.M. (2001) Cataract Blindness and Barriers to Uptake of Cataract Surgery in a Rural Community of Northern Nigeria. British Journal of Ophthalmology, 85, 776-780. https://doi.org/10.1136/bjo.85.7.776

[9] Patrick-Ferife, G., Ashaye, A.O. and Osuntokun, O. (2006). Rapid Assessment of Cataract Blindness among Ughelli Clan in an Urban/Rural District of Delta State, Nigeria. Annals of African Medicine, 4, 2-4.

[10] Klein, B.E., Klein, R., Wang, Q. and Moss, S.E. (1995) Older-Onset Diabetes and Lens Opacities. The Beaver Dam Eye Study. Ophthalmic Epidemiology, 2, 49-55. https://doi.org/10.3109/09286589509071451

[11] Kinoshita, J.H. (1974) Mechanisms Initiating Cataract Formation Proctor Lecture. Investigative Ophthalmology \& Visual Science, 13, 713-724.

[12] Jin, H.K. (1965) Cataracts in Galactosemia-The Jonas S. Friedenwald Memorial Lecture. Investigative Ophthalmology \& Visual Science, 4, 786-799.

[13] Weikel, K.A., Garber, C., Baburins, A. and Taylor, A. (2014) Nutritional Modulation of Cataract. Nutrition Reviews, 72, 30-47. https://doi.org/10.1111/nure.12077

[14] Braakhuis, A.J., Donaldson, C.I., Lim, J.C. and Donaldson, P.J. (2019) Nutritional Strategies to Prevent Lens Cataract: Current Status and Future Strategies. Nutrients, 11, 1186. https://doi.org/10.3390/nu11051186

[15] Sella, R. and Afshari, N.A. (2019) Nutritional Effect on Age-Related Cataract Formation and Progression. Current Opinion in Ophthalmology, 30, 63-69. https://doi.org/10.1097/ICU.0000000000000537

[16] Klein, R., Klein, B.E. and Moss, M.S. (1985) Prevalence of Cataracts in a Population-Based Study of Persons with Diabetes Mellitus. Ophthalmology, 92, 1191-1196. https://doi.org/10.1016/S0161-6420(85)33877-0

[17] Klein, R., Klein, B.E. and Moss, M.S. (1984) Visual Impairment in Diabetics. Ophthalmology, 91, 1-8. https://doi.org/10.1016/S0161-6420(84)34337-8

[18] Shui, Y.B., Holekamp, N.M., Kramer, B.C., Crowley, J.R., Wilkins, M.A., Chu, F., 
Malone, P.E., Mangers, S.J., Hou, J.H., Siegfried, C.J. and Beebe, D.C. (2009) The Gel State of the Vitreous and Ascorbate-Dependent Oxygen Consumption: Relationship to the Etiology of Nuclear Cataracts. Archives of Ophthalmology, 127, 475-482. https://doi.org/10.1001/archophthalmol.2008.621

[19] Senthilkumari, S., Talwar, B., Dharmalingam, K., Ravindran, R.D., Jayanthi, R., Sundaresan, P., Saravanan, C., Young, I.S., Dangour, A.D. and Fletcher, A.E. (2014) Polymorphisms in Sodium-Dependent Vitamin C Transporter Genes and Plasma, Aqueous Humor and Lens Nucleus Ascorbate Concentrations in an Ascorbate Depleted Setting. Experimental Eye Research, 124, 24-30.

https://doi.org/10.1016/j.exer.2014.04.022

[20] Siegfried, C.J., Shui, Y.B., Tian, B., Nork, T.M., Heatley, G.A. and Kaufman, P.L. (2017) Effects of Vitrectomy and Lensectomy on Older Rhesus Macaques: Oxygen Distribution, Antioxidant Status, and Aqueous Humor Dynamics. Investigative Ophthalmology \& Visual Science, 58, 4003-4014.

https://doi.org/10.1167/iovs.17-21890

[21] Siegfried, C.J. and Shui, Y.B. (2019) Intraocular Oxygen and Antioxidant Status: New Insights on the Effect of Vitrectomy and Glaucoma Pathogenesis. American Journal of Ophthalmology, 203, 12-25. https://doi.org/10.1016/j.ajo.2019.02.008

[22] Tessier, F., Moreaux, V., Birlouez-Aragon, I., Junes, P. and Mondon, H. (1998) Decrease in Vitamin C Concentration in Human Lenses during Cataract Progression. International Journal for Vitamin and Nutrition Research, 68, 309-315.

[23] Taylor, A., Jacques, P.F., Nadler, D., Morrow, F., Sulsky, S.I. and Shepard, D. (1991) Relationship in Humans between Ascorbic Acid Consumption and Levels of Total and Reduced Ascorbic Acid in Lens, Aqueous Humor, and Plasma. Current Eye Research, 10, 751-759. https://doi.org/10.3109/02713689109013869

[24] Yonova-Doing, E., Forkin, Z.A. and Hysi, P.G. (2016) Genetic and Dietary Factors Influencing the Progression of Nuclear Cataract. Ophthalmology, 123, 1237-1244. https://doi.org/10.1016/j.ophtha.2016.01.036

[25] Tan, A.G., Mitchell, P. and Flood, V.M. (2008) Antioxidant Nutrient Intake and the Long-Term Incidence of Age-Related Cataract: The Blue Mountains Eye Study. The American Journal of Clinical Nutrition, 87, 1899-1905.

https://doi.org/10.1093/ajcn/87.6.1899

[26] IBM SPSS Statistics for Windows, Version 23.0. IBM Corp., Armonk.

[27] Evans, E. (1934) Glutathione and Vitamin C in the Crystalline Lens. Nature, 134, 180-181. https://doi.org/10.1038/134180c0

[28] Tram, N.K., Maxwell, C.J. and Swindle-Reilly, K.E. (2021) Macro- and Microscale Properties of the Vitreous Humor to Inform Substitute Design and Intravitreal Bio Transport. Current Eye Research, 46, 429-444. https://doi.org/10.1080/02713683.2020.1826977

[29] Hashim, Z. and Zarina, S. (2006) Antioxidant Markers in Human Senile and Diabetic Cataractous Lenses. Journal of College of Physicians and Surgeons Pakistan, 16, 637-640.

[30] Canadananović, V., Latinović, S., Barišić, S., Babić, N. and Jovanovich, S. (2015) Age-Related Changes of Vitamin C Levels in Aqueous Humour. Vojnosanitetski Pregled, 72, 823-826. https://doi.org/10.2298/VSP131212063C

[31] Zheng Selin, J., Rautiainen, S., Lindblad, B.E., Morgenstern, R. and Wolk, A. (2013) High-Dose Supplements of Vitamins C and E, Low-Dose Multivitamins, and the Risk of Age-Related Cataract: A Population-Based Prospective Cohort Study of Men. American Journal of Epidemiology, 177, 548-555. 
https://doi.org/10.1093/aje/kws279

[32] Aragno, M., Mastrocola, R., Catalano, M.G., Brignardello, E., Danni1, O. and Boccuzzi, G. (2004) Oxidative Stress Impairs Skeletal Muscle Repair in Diabetic Rats. Diabetes, 53, 1082-1088. https://doi.org/10.2337/diabetes.53.4.1082 